\title{
Characterization of the effects of anti-aging medicine Fructus lycii on B-amyloid peptide neurotoxicity
}

\author{
MAN-SHAN YU ${ }^{1}$, CORA SAU-WAN LAI ${ }^{1}$, YUEN-SHAN HO ${ }^{1}$, SZE-YONG ZEE ${ }^{2}$, KWOK-FAI SO ${ }^{1,3,4}$, \\ WAI-HUNG YUEN ${ }^{5}$ and RAYMOND CHUEN-CHUNG CHANG ${ }^{1,3,4}$
}

\begin{abstract}
${ }^{1}$ Laboratory of Neurodegenerative Diseases, Department of Anatomy, LKS Faculty of Medicine, ${ }^{2}$ Department of Botany, ${ }^{3}$ Research Centre of the Heart, Brain, Hormone and Healthy Aging, ${ }^{4}$ Central Laboratory and ${ }^{5}$ Department of Chemistry and Open Laboratory of Chemical Biology of the Institute of Molecular Technology for Drug Discovery and Synthesis, The University of Hong Kong, Pokfulam, Hong Kong SAR, P.R. China
\end{abstract}

Received January 26, 2007; Accepted March 2, 2007

\begin{abstract}
Alzheimer's disease (AD) is an age-related neurodegenerative disease. There are increasing lines of evidence showing that the molecular signaling pathways in aged cells are altered so that cells are susceptible to injury. We and other laboratories have demonstrated the significant involvement of double-stranded RNA-dependent protein kinase (PKR) in B-amyloid (Aß) peptide neurotoxicity and in AD. Fructus lycii (the fruit of Lycium barbarum) has long been used in oriental medicine as an anti-aging agent. Our previous studies demonstrated that the aqueous extract isolated from L. barbarum exhibited significant protection on cultured neurons against harmful chemical toxins such as $A B$ and dithiothreitol. We also showed that the polysaccharidecontaining extract (LBP) from L. barbarum exhibited neuroprotective effects in the retina against ocular hypertension in a laser-induced glaucoma animal model. In this study, we aimed to investigate whether LBP can elicit neuroprotection to neurons stressed by $A ß$ peptides. Furthermore, we planned to isolate and identify the neuroprotective agent from LBP using chromatographic methods. Our results showed that pretreatment of LBP effectively protected neurons against $A \beta$-induced apoptosis by reducing the activity of both caspase- 3 and -2 , but not caspase- 8 and -9 . A new arabinogalactan-protein (LBP-III) was isolated from LBP and attenuated $A ß$ peptide-activated caspase-3-like activity.
\end{abstract}

Correspondence to: Dr Raymond C.-C. Chang, Department of Anatomy, LKS Faculty of Medicine, The University of Hong Kong, 21 Sassoon Road, Pokfulam, Hong Kong SAR, P.R. China

E-mail: rccchang@hkucc.hku.hk

Dr Wai-Hung Yuen, Department of Chemistry, Faculty of Science, The University of Hong Kong, Pokfulam Road, Pokfulam, Hong Kong SAR, P.R. China

E-mail: yuenwh@hkucc.hku.hk

Key words: Fructus lycii, arabinogalactan-protein, ß-amyloid peptide, neurotoxicity, neuronal apoptosis
LBP-III markedly reduced the phosphorylation of PKR triggered by $A B$ peptide. Since the phosphorylation state of PKR increased with age, reduction of its phosphorylation triggered by $\mathrm{A} \beta$ peptide may implicate that LBP-III from Fructus lycii is a potential neuroprotective agent in AD. As herbal medicine has received increasing attention for the treatment of $\mathrm{AD}$, our study will open a window for the development of a neuroprotective agent for anti-aging from Chinese medicine.

\section{Introduction}

Aging is usually associated with the reduction of physiological function, increases in the susceptibility for the progression of various neurodegenerative diseases as well as cancer development. It has been reported that aging and apoptosis are highly linked (1-3). Alzheimer's disease (AD) is an agerelated neurodegenerative disease with prominent pathological features of neuronal apoptosis $(4,5)$. To understand the biological mechanisms of aging and the increased susceptibility for neurons undergoing apoptosis in neurodegenerative diseases, we should at first elucidate the changes of intracellular signaling mechanisms. We were among the first to demonstrate that the double-stranded RNA-dependent serine/threonine kinase (PKR) plays significant roles in mediating $A ß$ neurotoxicity (6) and in $\mathrm{AD}$ (7). PKR is activated by phosphorylation when neurons are treated with $A ß$ peptides. Also, overexpression of wild-type PKR renders neurons more susceptible to $A \beta$ neurotoxicity (6). In postmortem AD brains, the level of phospho-PKR was elevated when compared to age-matched controls (7). This finding was further supported by other groups $(8,9)$. Moreover, it has been reported that the cellular level of PKR is known to slowly increase in aged cells (10).

To promote longevity, several strategies including physical exercise and caloric restriction are possible (11-13). Daily consumption of an anti-aging supplement such as a food supplement may be one of the methods to reduce the susceptibility of cells to environmental toxins. Among various food supplements, Fructus lycii (the dried ripe fruit 
of Lycium barbarum) has long earned its name as an antiaging tonic supplement in food and is one of the major components in recipes of many traditional Chinese medicinal formulas (14). Experimentally, the polysaccharide extracts of Fructus lycii have been shown to significantly prolong the life of the male Drosophila melanogaster (15). Another study demonstrated that $F$. lycii polysaccharide inhibits the nonenzyme glycation in a D-galactose-induced aging model in mice (16). Apart from the anti-aging effect, extracts from $F$. lycii are also cytoprotective in other cell types. It has been shown that polysaccharides isolated from $F$. lycii can significantly reduce $\mathrm{CCl}_{4}$-triggered liver toxicity (17). Also, it can exert protective effects against hyperthermia-induced damage in cultured seminiferous epithelium (18).

Our group has demonstrated the novel neuroprotective effects of the aqueous extract from Fructus lycii. We have proved that the extract isolated from the fruits of $F$. lycii markedly attenuated $A B$-induced apoptosis in cultured cortical neurons (19). Also, we have shown that Lycium barbarum extract was able to protect neurons against DTTinduced cell death (20). Apart from in vitro studies, we have recently shown that orally feeding rats with aqueous extract from $F$. lycii (LBP) significantly reduced the loss of retinal ganglion cells against ocular hypertension in a laser-induced glaucoma animal model (21). In this study, we aimed to investigate whether this LBP extract elicited neuroprotective effects against $A ß$ peptides. Our results here demonstrated that activation of caspase- 3 and -2 by $A B$ peptide was significantly reduced by pretreatment with LBP, indicating that LBP exhibited neuroprotective effects. To further investigate the chemical component of this extract, we attempted to separate the crude extracts by ion-exchange chromatography and found that only one fraction (LBP-III) was neuroprotective as shown by biochemical assay. LBP-III was found to be an arabinogalactan-protein with molecular weight $<30 \mathrm{kDa}$. By immunoblotting, LBP-III markedly decreased the protein level of Aß-activated phospho-PKR. Collectively analyzing all the experimental results, arabinogalactan-protein from Fructus lycii can be a potential candidate in the development of preventive treatments in neurodegenerative disorders such as AD.

\section{Materials and methods}

Materials. The fruits of Fructus lycii were harvested and purchased in Ningxia province, People's Republic of China. The glycosyl composition of the extract was determined by combined gas chromatography/mass spectroscopy (GC/MS) of the per- $O$-trimethylsilyl (TMS) derivatives of the monosaccharide methyl glycosides produced from the sample by acidic methanolysis. The molecular weight of LBP-III was determined by HPGPC. The analysis was performed by the Complex Carbohydrate Research Center, University of Georgia, Athens, GA and supported in part by the Department of the Energy-funded Center for Plant and Microbial Complex Carbohydrates (DF-FG09-93ER-20097). The amino acid composition analysis was determined by post-column ninhydrin detection on a Beckman amino acid analyzer instrument (Model 6300) performed by the Scientific Research Consortium, Inc. (St. Paul, MN, USA).
Preparation of LBP and separation of LBP-III. The extraction method is shown in Fig. 1. Briefly, the fruits of F. lycii $(10 \mathrm{~kg})$ were first soaked in $95 \%$ ethanol and stirred intermittently for $120 \mathrm{~h}$. The resultant residue was filtered and air-dried. The dried residue was dissolved in hot water $\left(70^{\circ} \mathrm{C}\right)$ twice, and the combined extracts were filtered and concentrated. The concentrated extract was incubated with trichloroacetic acid, dialyzed (molecular cut-off size 3000-5000 Da, Spectrum) against running water for 3 days and then precipitated with two volumes of $95 \%$ ethanol. The mixture was centrifuged and the precipitate was washed with absolute ethanol and acetone followed by vacuum-drying at $40^{\circ} \mathrm{C}$ for 2 days to give the crude extract LBP $(2 \mathrm{~g})$.

The crude extract LBP $(2 \mathrm{~g})$ was dissolved in water $(10 \mathrm{ml})$ and applied to a diethylaminoethylcellulose (DEAE)Sepharose fast flow column $\left(\mathrm{Cl}^{-}, 60 \times 5 \mathrm{~cm}\right.$, Amersham Biosciences, Little Chalfont, Buckinghamshire, UK) and eluted with water followed by a $0-0.5 \mathrm{M}$ gradient of $\mathrm{NaCl}$. The concentration of the carbohydrate was monitored by the phenol- $\mathrm{H}_{2} \mathrm{SO}_{4}$ method (22). Three fractions; LBP-I (0.09 g, $4.5 \%)$, LBP-II (0.12 g, 6.0\%) and LBP-III (0.088 g, 4.4\%) were obtained after dialysis (molecular cut-off size 3000$5000 \mathrm{Da})$ and lyophilized. All crude and purified extracts were examined for endotoxin (Sigma, St. Louis, MO, USA) and were proved to be endotoxin free.

Cell cultures and treatments. Primary neuronal cultures were prepared from day 17 embryonic Sprague-Drawley rats (Laboratory Animal Unit, The University of Hong Kong) according to our methods $(6,19,20,23-28)$. Briefly, after removal of the meninges the cortices were minced and plated onto poly-L-lysine- $(25 \mu \mathrm{g} / \mathrm{ml})$ coated 6 -well plates at $2 \times 10^{6}$ cells/well. Neurons were cultured with MEM supplemented with $5 \%$ fetal bovine serum (Gibco-BRL, Rockville, MO, USA). Neurons were maintained in a $5 \%$ $\mathrm{CO}_{2}$ incubator at $37^{\circ} \mathrm{C}$ prior to treatments. Cultured neurons at day 7 in vitro were pre-treated with LBP at various concentrations for $1 \mathrm{~h}$ and followed by incubation with $\mathrm{A} \beta_{25-35}$ (25 $\mu \mathrm{M}$, Sigma) for $24 \mathrm{~h}$.

Caspase activity assays. After treatments, cellular proteins were extracted for caspase activity assay. Briefly, treated cells were scratched and extracted in an ice-cold lysis buffer containing DTT (5 mM), EDTA (0.1 mM), HEPES (50 mM, $\mathrm{pH} 7.4)$ and Triton $\mathrm{X}-100(0.2 \%)$ without protease inhibitors. Fifty micrograms of cellular protein was incubated with the colorimetric caspase substrates: Ac-DEVE- $p$-NA for caspase-3, Ac-VDVAD- $p$ NA for caspase-2, Ac-IETD- $p$ NA for caspase-8, Ac-LEHD- $p$ NA for caspase- 9 and $p$ NA for the standard (Calbiochem, La Jolla, CA, USA) for $2 \mathrm{~h}$ at $37^{\circ} \mathrm{C}$, and then the absorbance of the yellow product ( $p$ NA) was measured at $405 \mathrm{~nm}$. Caspase activity was then calculated from the absorbance readings. Results were expressed as fold of control.

Western blot analysis. After treatments, cellular proteins were extracted in ice-cold lysis buffer as described previously $(6,19,20,23-28)$. Seventy micrograms of protein per lane were applied to SDS-PAGE (10\%) and then were transferred onto a PVDF membrane (Bio-Rad). After blocking, the 
(a)

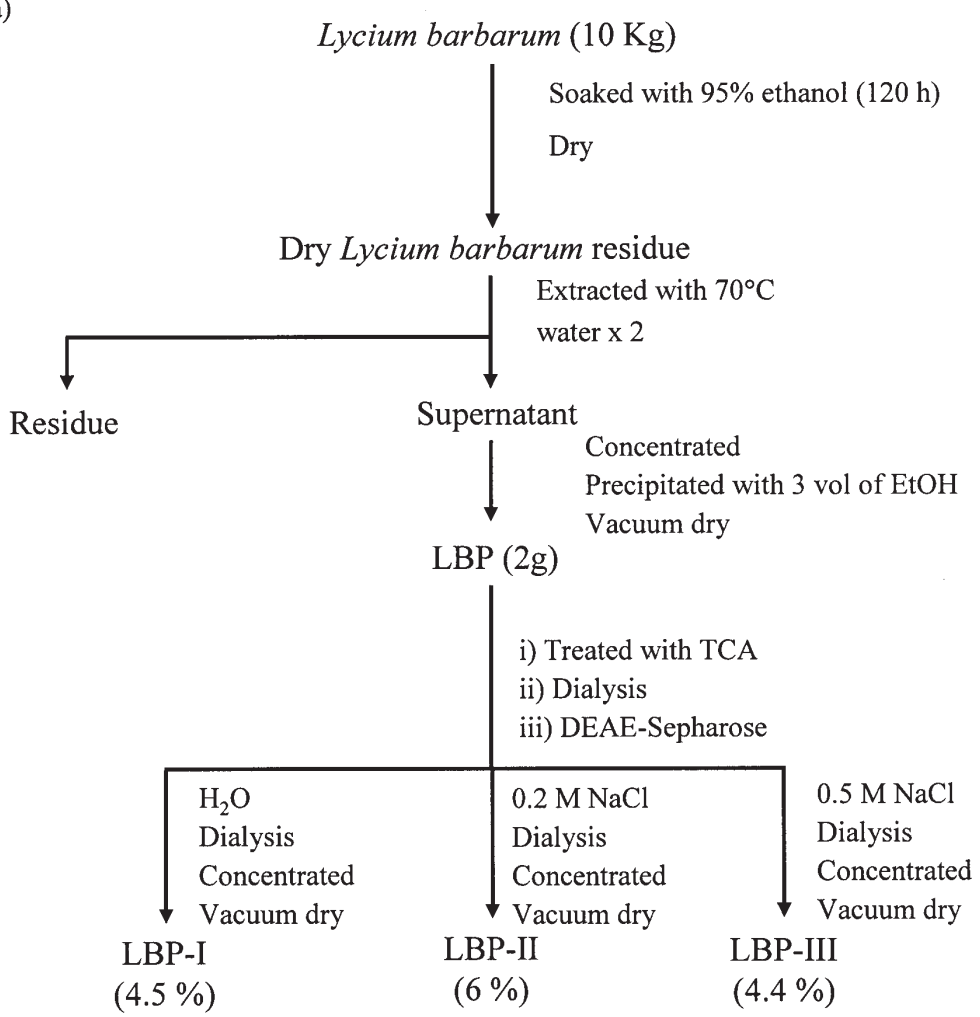

(b)

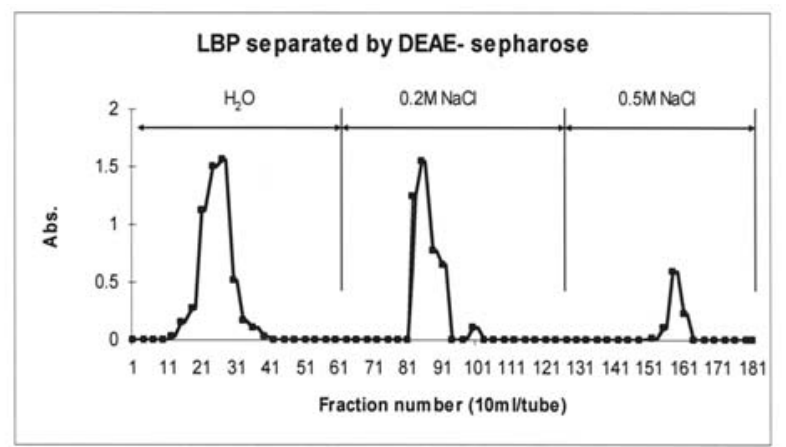

Figure 1. (a) Extraction scheme and isolation process of the aqueous extracts from Fructus lycii. (b) Elution profile of LBP on DEAE-Sepharose FF column $(60 \times 5 \mathrm{~cm})$; flow rate, $0.5 \mathrm{ml} / \mathrm{min}$.

membrane was incubated with the rabbit polyclonal antiphosphorylated PKR antibody $(1: 1000$, Cell Signaling Technology, Beverly, MA, USA), mouse monoclonal antiPKR antibody (1:1000, BD Transduction Laboratories, Lexington, KY, USA) or mouse monoclonal anti-ß-actin antibody (1:5000, Sigma) for $2 \mathrm{~h}$ at room temperature. The membrane was then incubated with goat anti-rabbit or goat anti-mouse HRP-conjugated secondary antibody (1:2000, Dako, Glostrup, Denmark) for $1 \mathrm{~h}$ at room temperature. The bands on X-ray film (Kodak, Tokyo, Japan) were developed by using chemiluminescent ECL method (Amersham Bioscience).

Statistical analysis. Data for multiple variable comparisons were analyzed by one-way analysis of variance (ANOVA). For the comparison of significance, Tukey's test was used as a post-hoc test according to the statistical program SigmaStat $^{\circledR}$ (Jandel Scientific, Chicago, IL, USA). A P value
$<0.05$ was considered to be statistically significant. Results were expressed as the mean \pm standard error (SE) from a minimum of three independent experiments.

\section{Results}

Neuroprotective effects of the extract from Fructus lycii $(L B P)$. To investigate the effects of the polysaccharide extract LBP from Fructus lycii on Aß-induced neurotoxicity, neurons were pre-incubated with different concentrations of LBP for $1 \mathrm{~h}$ and then treated with $\mathrm{A} \beta_{25-35}$ at $25 \mu \mathrm{M}$ for $24 \mathrm{~h}$. For apoptosis analysis, biochemical assays for caspase- 3 and -2 were investigated because both caspase- 3 and -2 had been demonstrated to be the major caspases for $A B$ peptide neurotoxicity $(6,28)$. LBP at $100 \mu \mathrm{g} / \mathrm{ml}$ significantly inhibited $A \beta$ peptide-stimulated caspase- 3 and -2 activities (Fig. 2). In Fig. 2a, when neurons were treated with $A B$ only, the caspase- 3 activity was $2.5 \pm 0.3$-fold of the control. 
(a)
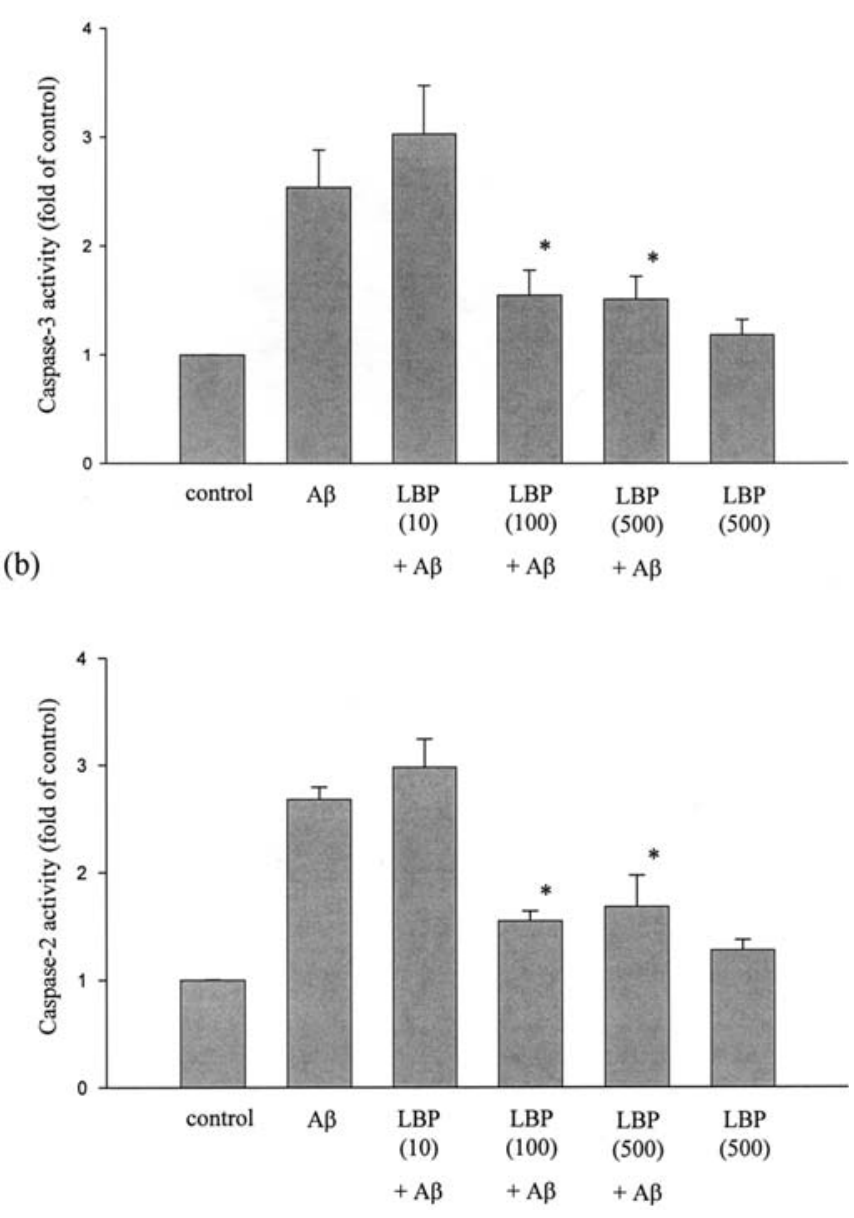

Figure 2. LBP attenuates $A \beta_{25-35}$ peptide-induced caspase-3 and caspase-2 activity. Primary cortical neurons were pretreated with different concentrations of LBP for $1 \mathrm{~h}$, then incubated with $25 \mu \mathrm{M}$ of $\mathrm{A}_{25-35}$ peptide for $24 \mathrm{~h}$. Proteins were extracted for colorimetric (a) caspase-3 and (b) caspase-2 activity assays. Results are expressed as fold of control as the mean \pm SE from three independent experiments. Significant difference is indicated by * $\mathrm{p}<0.05$ vs. the group treated with $A \beta_{25-35}$ peptide by one-way ANOVA for multi-group comparison followed by Tukey's post hoc test.

Pretreatment of LBP at $100 \mu \mathrm{g} / \mathrm{ml}$ markedly decreased the A $\beta$-activated caspase- 3 activity to $1.5 \pm 0.2$-fold of the control. Caspase-2 activity assay also showed similar results. As in Fig. 2b, the caspase- 2 activity was $2.7 \pm 0.1$-fold of the control in the $A ß$-treated group. For the group pre-treated with $100 \mu \mathrm{g} / \mathrm{ml}$ of LBP, the caspase-2 activity was lowered to $1.6 \pm 0.1$-fold of the control. However, a low concentration of LBP $(10 \mu \mathrm{g} / \mathrm{ml})$ did not significantly alter $\mathrm{A} B$ peptide toxicity to neurons. LBP at $500 \mu \mathrm{g} / \mathrm{ml}$ per se did not induce significant toxicity. While the activity of caspase-3 and -2 was significantly attenuated by LBP, it did not reduce Aßtriggered caspase- 8 and -9 activity (Fig. 3). The results suggest that LBP exerts differential neuroprotective effects on different pro-apoptotic pathways.

Carbohydrate analysis of the extracts from Fructus lycii. Since LBP exerted neuroprotective effects against A $B$ toxicity, it was essential to analyze the chemical composition of LBP and further isolate the active component of the extract. The carbohydrate analysis of LBP as shown in Table I (a)
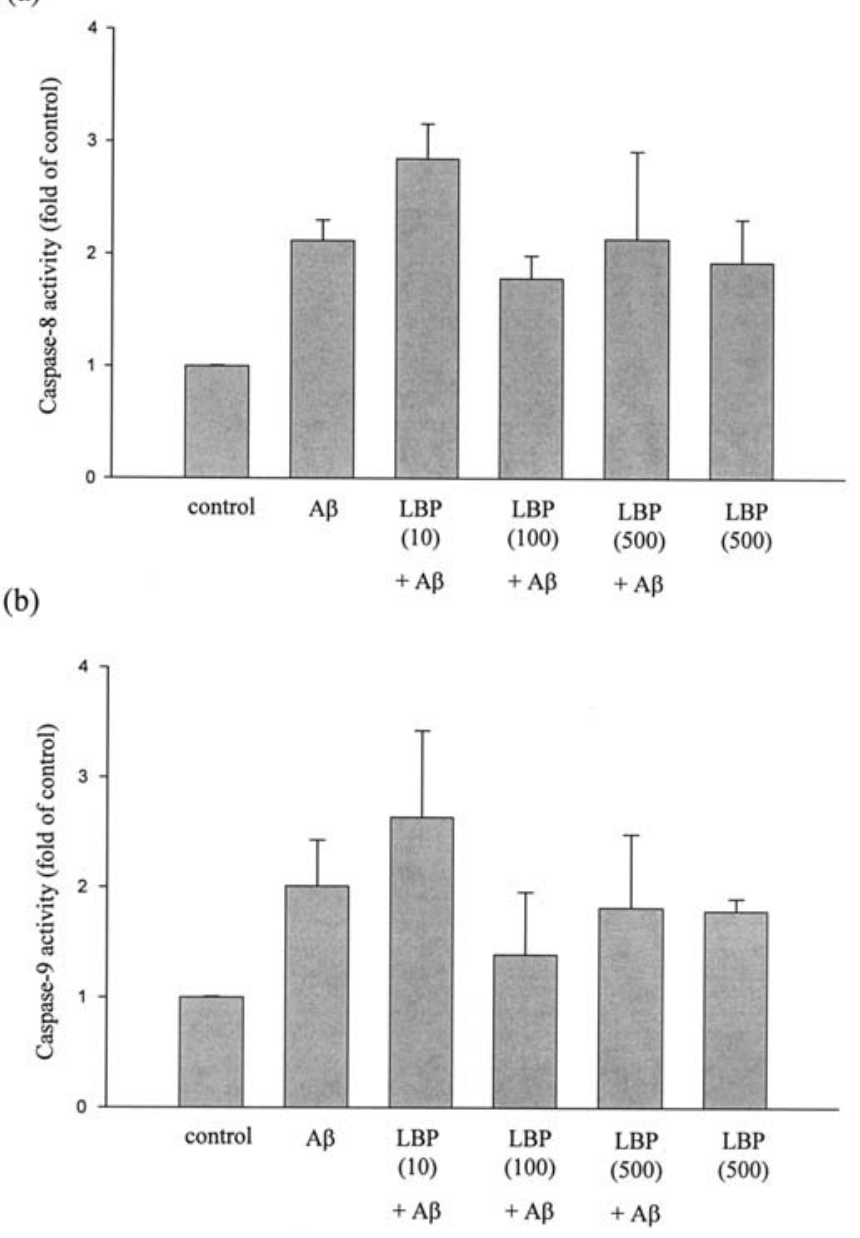

Figure 3. LBP does not significantly inhibit $A 3_{25-35}$ peptide-induced caspase- 8 and caspase- 9 activity. Primary cortical neurons were pretreated with different concentrations of LBP for $1 \mathrm{~h}$, followed by exposure to $25 \mu \mathrm{M}$ of $A \beta_{25-35}$ peptide for $24 \mathrm{~h}$. Proteins were extracted for colorimetric (a) caspase- 8 and (b) caspase-9 activity assays. Results are expressed as fold of control as the mean \pm SE from three independent experiments.

indicated that the glycosyl residues contain arabinose, rhamnose, xylose, mannose, galactose, glucose and galacturonic acid in the approximate ratio $16.1: 4.3: 2.8: 1.5: 12.9$ : $47.7: 14.4$ with a small amount of $\mathrm{N}$-acetyl glucosamine. LBP was then fractionated by DEAE-Sepharose column chromatography that was first eluted with water followed by stepwise elution using a $0.2 \mathrm{M} \mathrm{NaCl}$ and $0.5 \mathrm{M} \mathrm{NaCl}$ solution. All eluted fractions were monitored by a phenol-sulfuric acid test, dialysed and lyophilized. Carbohydrate composition analysis of these fractions revealed that they contained different ratios of monosaccharides. The analyzed results for LBP-I, LBP-II and LBP-III are also shown in Table I for comparison. From the results it was identified that LBP, LBP-I and LBP-II were presumed to be composed mainly of arabinogalactan ( 1:1.3 Ara:Gal) while galacturonic acid (GalA) was the major component of LBP-III. The methylation analysis result demonstrated that LBP-III consisted of 4-linked GalA, 3,4-linked GalA, 4-linked Glc, 2,3,4,6-linked Glc, 2-linked Rha and 3-linked GalA. The terminals of the chain consisted of GalA, Glc, Ara-f and Ara-p. T-GalA and 4-GalA were found to be the main components of LBP-III and this was compatible with the 
Table I. Composition of extracts isolated from Fructus lycii.

\begin{tabular}{|c|c|c|c|c|}
\hline & LBP & LBP-I & LBP-II & LBP-III \\
\hline Protein $^{\mathrm{a}}$ & 8.6 & 9.9 & 40.6 & 6.3 \\
\hline Neutral sugars ${ }^{\mathrm{a}}$ & 18.0 & 55.0 & 26.0 & 15.0 \\
\hline Arabinose $^{b}$ & 16.1 & 49.8 & 35.1 & 6.1 \\
\hline Rhamnose $^{b}$ & 4.3 & - & 9.2 & 1.5 \\
\hline Xylose ${ }^{b}$ & 2.8 & 5.3 & 2.4 & - \\
\hline Glucuronic acid ${ }^{\mathrm{b}}$ & - & 1.1 & 3.3 & - \\
\hline Galacturonic acid ${ }^{\mathrm{b}}$ & 14.4 & - & 5.0 & 92.4 \\
\hline Mannose $^{b}$ & 1.5 & 2.0 & 0.8 & - \\
\hline Galactose $^{\mathrm{b}}$ & 12.9 & 32.2 & 33.3 & - \\
\hline Glucose $^{\mathrm{b}}$ & 47.7 & 9.6 & 10.9 & - \\
\hline $\mathrm{N}$-acetyl glucosamine ${ }^{\mathrm{b}}$ & 0.3 & - & - & - \\
\hline
\end{tabular}

a\% dry-weight basis; ${ }^{b} \mathrm{~mol} \%$.

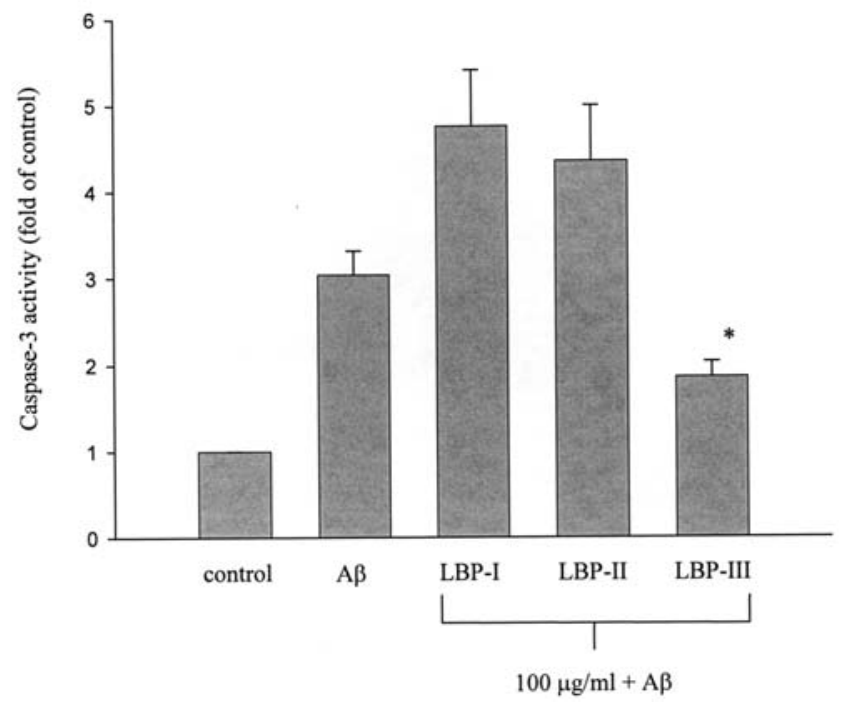

Figure 4. Neuroprotective effects of fractionated extracts from LBP against $\mathrm{A} \beta_{25-35}$ peptide toxicity. Primary cortical neurons were pretreated with three different fractions of LBP $(100 \mu \mathrm{g} / \mathrm{ml})$ for $1 \mathrm{~h}$, followed by exposure to $25 \mu \mathrm{M}$ of $\mathrm{A}_{25-35}$ peptide for $24 \mathrm{~h}$. Proteins were extracted for colorimetric caspase- 3 activity assay. Only the LBP-III fraction attenuated $A \beta_{25-35}$ peptide-triggered caspase- 3 activity. Results are expressed as fold of control as the mean $\pm \mathrm{SE}$ from three independent experiments. Significant difference is indicated by ${ }^{*} \mathrm{p}<0.05$ vs. the group treated with $A \beta_{25-35}$ peptide by one-way ANOVA for multi-group comparison followed by Tukey's post hoc test.

result of the glycosyl composition analysis. The molecular weight of LBP-III was estimated to be $<30 \mathrm{kDa}$ by HPGPC.

Amino acid analysis of the extracts from Fructus lycii. LBP contained $8.6 \%$ protein. The three isolated fractions, LBP-I, LBP-II and LBP-III contained 9.9\%, $40.6 \%$ and $6.3 \%$ protein, respectively (Table I). The amino acid analysis of these extracts is shown in Table II. Aspartic acid, glutamic acid, serine and cysteine were the major amino acids in LBP. After the fractionation procedures, cysteine, aspartic acid and
Table II. The amino acid composition of extracts isolated from Fructus lycii.

\begin{tabular}{lrrrr}
\hline \multirow{2}{*}{ Amino acid } & \multicolumn{4}{c}{ Mol \% } \\
\cline { 2 - 5 } & LBP & LBP-I & LBP-II & LBP-III \\
\hline Asp & 27.38 & 11.03 & 14.33 & 13.59 \\
Glu & 13.02 & 11.92 & 9.92 & 18.54 \\
Ser & 8.25 & 6.31 & 7.96 & 6.82 \\
Gly & 4.52 & 7.96 & 8.86 & 8.14 \\
His & 3.01 & 1.80 & 1.94 & 2.54 \\
Arg & 4.58 & 2.52 & 2.95 & 2.53 \\
Thr & 4.04 & 5.29 & 6.21 & 5.56 \\
Ala & 7.07 & 6.23 & 11.15 & 4.94 \\
Pro & 4.41 & 6.05 & 6.30 & 7.69 \\
Tyr & 1.48 & 1.93 & 2.90 & 2.74 \\
Val & 1.25 & 2.61 & 3.09 & 3.25 \\
Met & 0.00 & 0.82 & 0.04 & 0.43 \\
Cys & 10.49 & 18.28 & 4.01 & 6.04 \\
Ile & 0.96 & 2.07 & 2.57 & 1.74 \\
Leu & 1.92 & 5.20 & 4.02 & 3.72 \\
Phe & 1.01 & 1.81 & 2.41 & 1.72 \\
Lys & 2.72 & 4.73 & 7.93 & 3.87 \\
Ammonia & 3.89 & 3.45 & 3.41 & 6.14 \\
Total & 100.00 & 100.00 & 100.00 & 100.00 \\
\hline
\end{tabular}

glutamic acid became the major amino acid group of LBP-I, LBP-II and LBP-III, respectively.

Neuroprotective effects of fractionated extracts from LBP. Having separated different fractions by the ion-exchange chromatographic method, we further examined which fraction exerted neuroprotective effects. The activity of caspase-3 served as an index for neuronal apoptosis. Among three different fractions, it was interesting to find that only the LBP-III fraction attenuated Aß peptide-triggered caspase- 3 activity (Fig. 4). The results suggest that the $0.5 \mathrm{M} \mathrm{NaCl}-$ eluted product from LBP contains neuroprotective components against $A ß$ peptide neurotoxicity. The biochemical analysis of caspase- 3 activity was confirmed by morphological examination (Fig. 5). Upon exposure to $A ß$ peptide, neurites were broken and neurons were undergoing apoptosis (Fig. 5b). However, neurons pre-treated with LBP-III preserved the fasciculation of neurites and the integrity of neurons (Fig. 5c and d).

LBP-III fraction reduces the phosphorylation of $P K R$ in $A \beta$ toxicity. When neurons were treated with $\mathrm{A} \beta$ peptides, PKR was activated via phosphorylation. Phospho-PKR can phosphorylate eIF $2 \alpha$, which may inhibit the initiation of protein translation and cause neuronal apoptosis (6). Since LBP-III exhibits neuroprotective effects against $A B$ toxicity, we investigated whether the neuroprotection was mediated via the PKR pathway. By Western blot analysis, neurons treated with $A \beta$ peptides alone enhanced the phosphorylation of PKR (Fig. 6). Pretreatment of LBP-III at 100 and $500 \mu \mathrm{g} / \mathrm{ml}$ 

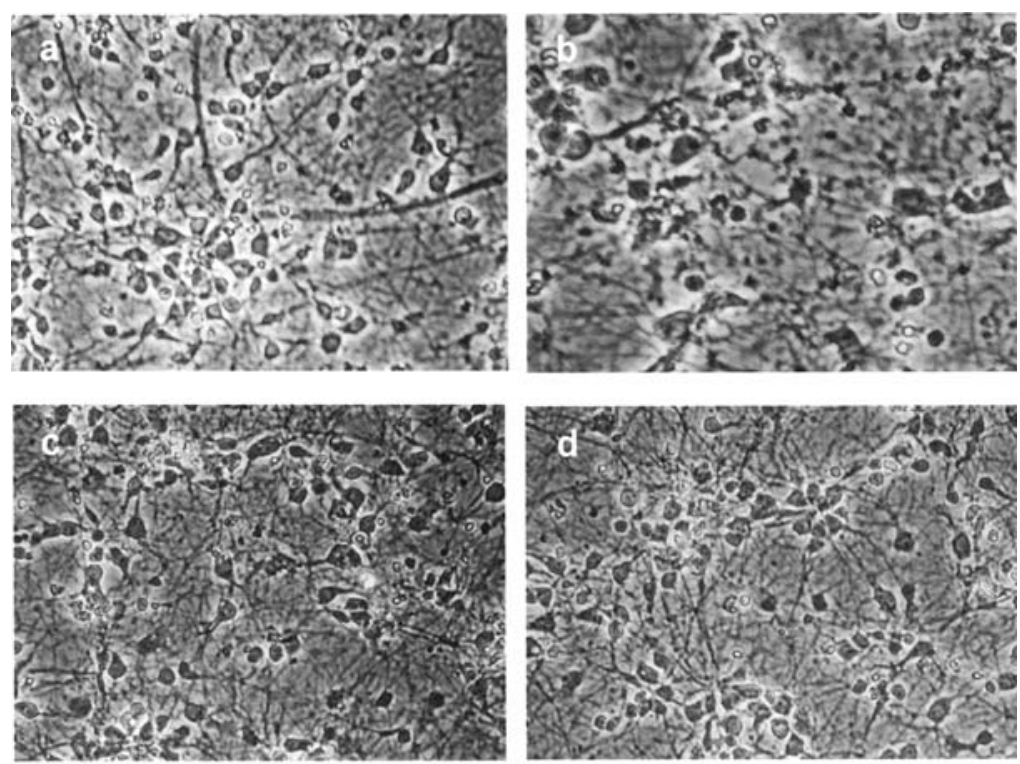

$50 \mu \mathrm{m}$

Figure 5. Morphology of neurons treated with LBP-III fraction and $\mathrm{A}_{25-35}$ peptide. Neurons were pre-incubated with LBP-III (100 and $\left.500 \mu \mathrm{g} / \mathrm{ml}\right)$ for $1 \mathrm{~h}$, followed by a 24-h exposure to $25 \mu \mathrm{M}$ of $\mathrm{A}_{25-35}$. Morphology of neurons after different treatments: (a) control, (b) $\mathrm{A} \beta_{25-35}$ (25 $\left.\mu \mathrm{M}\right)$, (c) LBP-III (100 $\left.\mu \mathrm{g} / \mathrm{ml}\right)+$ $\mathrm{AB}_{25-35}(25 \mu \mathrm{M})$ and (d) LBP-III $(500 \mu \mathrm{g} / \mathrm{ml})+\mathrm{AB}_{25-35}(25 \mu \mathrm{M})$.

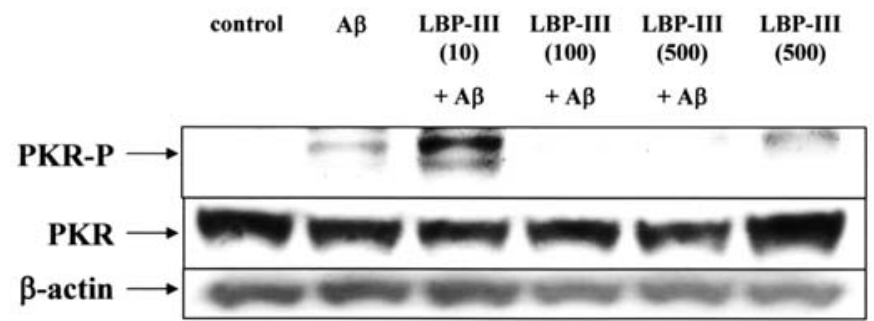

Figure 6. Effects of the LBP-III fraction on the inhibition of phosphorylation of PKR stimulated by $A \beta_{25-35}$ peptide. Neurons were pretreated with LBP-III $(10,100$ and $500 \mu \mathrm{g} / \mathrm{ml})$ for $1 \mathrm{~h}$, followed by a $4-\mathrm{h}$ exposure to $25 \mu \mathrm{M}$ of $\mathrm{A} \beta_{25-35}$. Immunoblotting was performed to determine the level of phosphorylated PKR (Thr446/451), total PKR and B-actin (used as the internal control).

markedly reduced the level of phospho-PKR after exposure to $A ß$ peptide for $4 \mathrm{~h}$. The protein levels of total PKR and $\beta$-actin remained unchanged after the treatment.

\section{Discussion}

Our results here showed that a polysaccharide-containing extract (LBP) for anti-aging from oriental medicine Fructus lycii exerted neuroprotective effects against $A B$ peptide neurotoxicity. LBP was capable of attenuating Aß-triggered activation of caspase- 3 and -2 but not caspase- 8 and -9 . These results suggest that the polysaccharide-containing extract from Fructus lycii exerts differential effects on pro-apoptotic signaling pathways. In order to find out the active components in LBP, we used ion-exchange chromatography to semipurify LBP into three different fractions: LBP-I, LBP-II and LBP-III. We also investigated the chemical nature of all the extracts. Among the three isolated fractions, only LBP-III elicited neuroprotection against $A ß$ toxicity as revealed by caspase- 3 activity assay. To further examine the underlying mechanisms of its neuroprotective effects, we found that LBP-III attenuated Aß-triggered activation of PKR. As we have shown that PKR plays significant roles in $A ß$ neurotoxicity (6) and $\mathrm{AD}(7)$, our results indicate that arabinogalactan-protein from Fructus lycii may be a potential neuroprotective agent.

Therapies for anti-aging have long been studied in many laboratories $(13,29,30)$. While caloric restriction, appropriate exercise and anti-oxidants have been reported to exert beneficial effects towards any anti-aging program $(11,31,32)$, only few laboratories have focused on the change of intracellular signaling to reduce susceptibility for the development of degenerative diseases (33-35). The concept of neuroprotection is therefore important to minimize or slow the degenerative processes of neurons. Oriental herbs have a wide array of anti-aging drugs that have long been known to nourish and enhance the health of our bodies (14). However, their working mechanisms are still unclear; and therefore, we aim to elucidate both the chemistry and molecular mechanisms of these anti-aging drugs.

The anti-aging effects of Fructus lycii have been extensively investigated in recent years. Different research groups have explored the potential of extracts from Fructus lycii in anti-aging or age-related diseases. Cheng et al have demonstrated that daily intake of fruits of Fructus lycii can increase the fasting plasma zeaxanthin, which may effectively prevent age-related macular degeneration (36). Recently, we isolated and examined the neuroprotective effects of an aqueous extract with a different purification method from Fructus lycii against Aß toxicity (19). Preliminary studies suggested that cultured neurons pre-treated with Fructus lycii extract could attenuate $A B$-induced apoptosis via the 
inhibition of the JNK pathway. In an in vivo study, we showed that LBP extracted from the aqueous extract of Fructus lycii was capable of significantly reducing the loss of retinal ganglion cells triggered by ocular hypertension in an animal model of glaucoma (21). Since different laboratories use different extraction methods to prepare polysaccharidecontaining extract, it is important to confirm that polysaccharide-containing extracts from $F$. lycii can effectively protect neurons from neurodegeneration, such as in $\mathrm{AD}$ and glaucoma. Together with the previous studies, our results here agree with the hypothesis that extracts isolated from $F$. lycii exhibit neuroprotective effects. In future, more studies will be carried out to investigate whether extracts from $F$. lycii can be applied to different age-related diseases.

$\mathrm{A} ß$ peptide-induced neuronal apoptosis has long been investigated. In fact, apoptosis is well documented in both in vivo and in vitro studies. Activation of caspase- 3 has been observed in postmortem $\mathrm{AD}$ brain sections, suggesting that neuronal apoptosis does occur in AD (37). In addition, significant roles of caspase- 2 in $A ß$ neurotoxicity have been reported (38). Activation of caspase- 8 via Fas or tumor necrosis factor receptor (TNFR) by $A B$ peptide and in $A D$ has also been demonstrated (39-42). We reported an early activation of caspase- 8 in neurons upon exposure to $A ß$ peptide (28). While many reports have shown the significant roles of apoptosis in $\mathrm{AD}$-related neurodegeneration, current therapeutic intervention often focuses on the inhibition of acetylcholinesterase to preserve the acetylcholine level in the brain. However, if neurons are approaching degeneration via apoptosis, intervention of apoptotic machinery is far more important than that of a neurotransmitter to preserve neurons. Therefore, the activity of these caspases was examined in our study. Reduction of caspase- 3 and -2 without the attenuation of caspase- 8 suggests that neuroprotective effects from Fructus lycii are not mediated via Fas or TNFR.

Activation of caspase- 9 can be accompanied by i) cleavage of Bid by caspase- 8 to induce cytochrome c release and subsequent activation of caspase-9 (43); ii) activation of caspase- 2 to alter mitochondrial permeability and trigger cytochrome c release that can activate caspase-9 (44-46); or iii) calcium overload of mitochondria to trigger cytochrome $\mathrm{c}$ release and activation of caspase-9 (47). While our results show a reduction of caspase- 2 but not caspase- 9 , it is not possible that activation of caspase- 9 in our experimental model was achieved by possibility (ii). Therefore, only (i) and (iii) are possible to explain how caspase- 9 was activated in our experimental model. We have shown that attenuation of Aß-triggered intracellular calcium increase by inositol 1,4,5trisphosphate receptor antagonists, 2-aminoethoxydiphenyl borate (2APB) or xestospongin $\mathrm{C}$, cannot reduce caspase-9 activity (27). Thus, calcium will not be a factor triggering mitochondrial overload and subsequent activation of caspase- 9 . Since caspase- 8 activity was not significantly reduced by LBP, caspase- 9 seems to be activated by the activation of caspase- 8 in $A ß$ neurotoxicity.

During the investigation of the molecular mechanism of the neuroprotective extract, it was interesting to reveal that LBP-III attenuated the PKR pathway. As stated before, we are the first laboratory to demonstrate that PKR plays significant roles in $\mathrm{A} \beta$ neurotoxicity and in $\operatorname{AD}(6,7,28)$. It has been confirmed by other laboratories using APP transgenic mice and postmortem human $\mathrm{AD}$ brain sections $(8,9)$. Activation of the PKR pathway is not specific to $A B$ neurotoxicity or to AD. However, PKR can trigger a cascade of pro-apoptotic signaling once it is activated $(48,49)$. Therefore, reduction of its activation will exert beneficial effects to prevent commitment of neuronal apoptosis. This implies that LBP-III may not only protect neurons against $\mathrm{A} \beta$-induced apoptosis, but also has the potential to elicit neuroprotection against other toxins or stresses. Together with evidence from the carbohydrate analysis, LBP-III contains mainly arabinogalacturonate. Although neuroprotective LBP-III contains a high content of galacturonate, application of polygalacturonic acid did not provide any significant neuroprotection against $A ß$ peptide neurotoxicity (data not shown). This suggests that components other than galacturonate may be responsible for the neuroprotection against $A ß$ toxicity. Further fractionation of LBP-III may help us determine the active component in Fructus lycii that contributes to neuroprotective effects.

Collectively, we present anti-aging herbs from oriental medicine that can attenuate $A ß$ peptide neurotoxicity. We have elucidated the chemical nature and molecular mechanisms of how polysaccharide-containing extracts safeguard neurons. These results will provide a lead for animal and even human studies in the future. Investigation of anti-aging drugs not only opens a new avenue for drug development, but also helps us to understand the chemistrybiology functional relationship. As previously stated, oriental herbs contain many valuable anti-aging drugs (14). The elucidation of their molecular mechanisms will definitely pave a road for a better longevity-promotion program. In addition, the application of neuroprotective agents will certainly prevent age-related neurodegenerative diseases.

\section{Acknowledgements}

We thank Miss Fanny Kam for her technical help in preparing neuronal cell cultures. This study was supported by University Strategic Theme Research on Healthy Aging, Research Fund for the Control of Infectious Disease (no. 05050032) from Health, Welfare and Food Bureau, CERG (nos. 7699/05M and 7552/06M), HKU Seed Funding for Basic Research (no. 200511159072) to RCCC, full studentship from the graduate school to MSY, CSL and YSH and is a part for Area of Excellence (AoE/P-10/01).

\section{References}

1. Higami $\mathrm{Y}$ and Shimokawa I: Apoptosis in the aging process. Cell Tissue Res 301: 125-132, 2000

2. Zhang JH, Zhang Y and Herman B: Caspases, apoptosis and aging. Ageing Res Rev 2: 357-366, 2003.

3. Zhang Y and Herman B: Ageing and apoptosis. Mech Ageing Dev 123: 245-260, 2002.

4. Bamberger ME and Landreth GE: Inflammation, apoptosis, and Alzheimer's disease. Neuroscientist 8: 276-283, 2002.

5. Roth KA: Caspases, apoptosis, and Alzheimer disease: causation, correlation, and confusion. J Neuropathol Exp Neurol 60: 829-838, 2001.

6. Chang RCC, Suen KC, Ma CH, Elyaman W, Ng HK and Hugon J: Involvement of double-stranded RNA-dependent protein kinase and phosphorylation of eukaryotic initiation factor-2alpha in neuronal degeneration. J Neurochem 83: 1215-1225, 2002. 
7. Chang RCC, Wong AK, Ng HK and Hugon J: Phosphorylation of eukaryotic initiation factor-2alpha (eIF2alpha) is associated with neuronal degeneration in Alzheimer's disease. Neuroreport 13: 2429-2432, 2002.

8. Peel AL and Bredesen DE: Activation of the cell stress kinase PKR in Alzheimer's disease and human amyloid precursor protein transgenic mice. Neurobiol Dis 14: 52-62, 2003.

9. Onuki R, Bando Y, Suyama E, Katayama T, Kawasaki H, Baba T, Tohyama M and Taira K: An RNA-dependent protein kinase is involved in tunicamycin-induced apoptosis and Alzheimer's disease. EMBO J 23: 959-968, 2004.

10. Ladiges W, Morton J, Blakely C and Gale M: Tissue specific expression of PKR protein kinase in aging B6D2F1 mice. Mech Ageing Dev 114: 123-132, 2000.

11. Lane MA, Black A, Handy A, Tilmont EM, Ingram DK and Roth GS: Caloric restriction in primates. Ann NY Acad Sci 928: 287-295, 2001

12. Mattson MP, Duan W, Chan SL, Cheng A, Haughey N, Gary DS, Guo Z, Lee J and Furukawa K: Neuroprotective and neurorestorative signal transduction mechanisms in brain aging: modification by genes, diet and behavior. Neurobiol Aging 23: 695-705, 2002.

13. Yu BP: Approaches to anti-aging intervention: the promises and the uncertainties. Mech Ageing Dev 111: 73-87, 1999.

14. Chen $\mathrm{K}$ and Li C: Recent advances in studies on traditional Chinese anti-aging materia medica. J Tradit Chin Med 13: 223-226, 1993.

15. Wang J, Wang $\mathrm{H}$, Zhang $\mathrm{M}$ and Zhang S: Anti-aging function of polysaccharides from Fructus lycii. Acta Nutrimenta Sinica 2: 81-83, 2002.

16. Deng HB, Cui DP, Jiang JM, Feng YC, Cai NS and Li DD: Inhibiting effects of Achyranthes bidentata polysaccharide and Lycium barbarum polysaccharide on nonenzyme glycation in Dgalactose-induced mouse aging model. Biomed Environ Sci 16: 267-275, 2003.

17. Kim SY, Lee EJ, Kim HP, Kim YC, Moon A and Kim YC: A novel cerebroside from lycii fructus preserves the hepatic glutathione redox system in primary cultures of rat hepatocytes. Biol Pharm Bull 22: 873-875, 1999.

18. Wang Y, Zhao H, Sheng X, Gambino PE, Costello B and Bojanowski K: Protective effect of Fructus Lycii polysaccharides against time and hyperthermia-induced damage in cultured seminiferous epithelium. J Ethnopharmacol 82: 169-175, 2002.

19. Yu MS, Leung SKY, Lai SW, Che CM, Zee SY, So KF, Yuen WH and Chang RCC: Neuroprotective effects of antiaging oriental medicine Lycium barbarum against beta-amyloid peptide neurotoxicity. Exp Gerontol 40: 716-727, 2005.

20. Yu MS, Ho YS, So KF, Yuen WH and Chang RCC: Cytoprotective effects of Lycium barbarum against reducing stress on endoplasmic reticulum. Int J Mol Med 17: 1157-1161, 2006.

21. Chan HC, Chang RCC, Ip AKC, Chiu K, Yuen WH, Zee SY and So KF: Neuroprotective effects of Lycium barbarum Lynn on protecting retinal ganglion cells in an ocular hypertension model of glaucoma. Exp Neurol 203: 269-273, 2007.

22. Dubois M, Gilles K, Hamilton JK, Rebers PA and Smith F: Colorimetric method for determination of sugars and related substances. Anal Chem 28: 350-354, 1956.

23. Lai SW, Yu MS, Yuen WH and Chang RCC: Novel neuroprotective effects of the aqueous extracts from Verbena officinalis Linn. Neuropharmacology 50: 641-650, 2006.

24. Lin KF, Chang RCC, Suen KC, So KF and Hugon J: Modulation of calcium/calmodulin kinase-II provides partial neuroprotection against beta-amyloid peptide toxicity. Eur $\mathbf{J}$ Neurosci 19: 2047-2055, 2004.

25. Yu MS, Lai SW, Lin KF, Fang JN, Yuen WH and Chang RCC: Characterization of polysaccharides from the flowers of Nerium indicum and their neuroprotective effects. Int J Mol Med 14: 917-924, 2004

26. Yu MS, Suen KC, Kwok NS, So KF, Hugon J and Chang RCC: Beta-amyloid peptides induce neuronal apoptosis via a mechanism independent of unfolded protein responses. Apoptosis 11: 687-700, 2006.

27. Suen KC, Lin KF, Elyaman W, So KF, Chang RCC and Hugon J: Reduction of calcium release from the endoplasmic reticulum could only provide partial neuroprotection against beta-amyloid peptide toxicity. J Neurochem 87: 1413-1426, 2003.
28. Suen KC, Yu MS, So KF, Chang RCC and Hugon J: Upstream signaling pathways leading to the activation of double-stranded RNA-dependent serine/threonine protein kinase in beta-amyloid peptide neurotoxicity. J Biol Chem 278: 49819-49827, 2003.

29. Mattson MP: Gene-diet interactions in brain aging and neurodegenerative disorders. Ann Intern Med 139: 441-444, 2003.

30. Mattson MP, Duan W and Guo Z: Meal size and frequency affect neuronal plasticity and vulnerability to disease: cellular and molecular mechanisms. J Neurochem 84: 417-431, 2003.

31. Brewer GJ: Neuronal plasticity and stressor toxicity during aging. Exp Gerontol 35: 1165-1183, 2000.

32. Lane MA, Ingram DK and Roth GS: The serious search for an anti-aging pill. Sci Am 287: 36-41, 2002.

33. Zhu X, Rottkamp CA, Boux H, Takeda A, Perry G and Smith MA: Activation of p38 kinase links tau phosphorylation, oxidative stress, and cell cycle-related events in Alzheimer's disease. J Neuropathol Exp Neurol 59: 880-888, 2000

34. Zhu X, Raina AK, Perry G and Smith MA: Alzheimer's disease: the two-hit hypothesis. Lancet Neurol 3: 219-226, 2004.

35. Zhu X, Raina AK, Rottkamp CA, Aliev G, Perry G, Boux H and Smith MA: Activation and redistribution of c-jun N-terminal kinase/stress activated protein kinase in degenerating neurons in Alzheimer's disease. J Neurochem 76: 435-441, 2001.

36. Cheng CY, Chung WY, Szeto YT and Benzie IF: Fasting plasma zeaxanthin response to Fructus barbarum L. (wolfberry; Kei Tze) in a food-based human supplementation trial. Br J Nutr 93: 123-130, 2005.

37. Su JH, Zhao M, Anderson AJ, Srinivasan A and Cotman CW: Activated caspase-3 expression in Alzheimer's and aged control brain: correlation with Alzheimer pathology. Brain Res 898: 350-357, 2001.

38. Troy CM, Rabacchi SA, Friedman WJ, Frappier TF, Brown K and Shelanski ML: Caspase-2 mediates neuronal cell death induced by beta-amyloid. J Neurosci 20: 1386-1392, 2000.

39. Li R, Yang L, Lindholm K, Konishi Y, Yue X, Hampel H, Zhang D and Shen Y: Tumor necrosis factor death receptor signaling cascade is required for amyloid-beta protein-induced neuron death. J Neurosci 24: 1760-1771, 2004.

40. Rohn TT, Head E, Nesse WH, Cotman CW and Cribbs DH: Activation of caspase- 8 in the Alzheimer's disease brain. Neurobiol Dis 8: 1006-1016, 2001

41. Ivins KJ, Thornton PL, Rohn TT and Cotman CW: Neuronal apoptosis induced by beta-amyloid is mediated by caspase- 8 . Neurobiol Dis 6: 440-449, 1999.

42. Cantarella G, Uberti D, Carsana T, Lombardo G, Bernardini R and Memo M: Neutralization of TRAIL death pathway protects human neuronal cell line from beta-amyloid toxicity. Cell Death Differ 10: 134-141, 2003

43. Li H, Zhu H, Xu CJ and Yuan J: Cleavage of BID by caspase 8 mediates the mitochondrial damage in the Fas pathway of apoptosis. Cell 94: 491-501, 1998.

44. Lassus P, Opitz-Araya X and Lazebnik Y: Requirement for caspase-2 in stress-induced apoptosis before mitochondrial permeabilization. Science 297: 1352-1354, 2002.

45. Paroni G, Henderson C, Schneider C and Brancolini C: Caspase-2 can trigger cytochrome $\mathrm{C}$ release and apoptosis from the nucleus. J Biol Chem 277: 15147-15161, 2002.

46. Paroni G, Henderson C, Schneider C and Brancolini C: Caspase-2-induced apoptosis is dependent on caspase-9, but its processing during UV- or tumor necrosis factor-dependent cell death requires caspase-3. J Biol Chem 276: 21907-21915, 2001.

47. Jambrina E, Alonso R, Alcalde M, del Carmen RM, Serrano A, Martinez A, Garcia-Sancho J and Izquierdo M: Calcium influx through receptor-operated channel induces mitochondriatriggered paraptotic cell death. J Biol Chem 278: 14134-14145, 2003.

48. Hsu LC, Park JM, Zhang K, Luo JL, Maeda S, Kaufman RJ, Eckmann L, Guiney DG and Karin M: The protein kinase PKR is required for macrophage apoptosis after activation of Tolllike receptor 4. Nature 428: 341-345, 2004.

49. Takizawa T, Tatematsu $C$ and Nakanishi Y: Double-stranded RNA-activated protein kinase interacts with apoptosis signalregulating kinase 1 . Implications for apoptosis signaling pathways. Eur J Biochem 269: 6126-6132, 2002. 